\title{
Enhancement of Nitrogen and Phosphorus Removal in an Anaerobic/Oxic/Anoxic Sequencing Batch Reactor as Affected by the Amount of External Carbon
}

\author{
Koichi SOEJIMA*, Akihiko TERADA**, Kensuke NARAKI***, Satoshi TSUNEDA*** \\ *MAYEKAWA MFG. Co., Ltd., Moriya Factory, Research and Development Center, Ibaraki \\ 302-0118, Japan \\ **Department of Chemical Engineering, Tokyo University of Agriculture and Technology, \\ Tokyo 184-8588, Japan \\ ***Department of Life Science and Medical Bioscience, Waseda University, Tokyo 162-8480, \\ Japan
}

\begin{abstract}
The effect of external carbon (acetate) addition on nitrogen and phosphorus removal in a sequencing batch reactor (SBR) employing anaerobic/oxic/anoxic (AOA) regime was investigated. Two SBRs, receiving wastewater with different total organic carbon per nitrogen concentration $(\mathrm{TOC} / \mathrm{N}$ ) ratios (influent TOC/N ratio: 2.2 and 4.5 in Run 1 and Run 2, respectively) were operated by changing the amount of external carbon addition at the beginning of oxic phase. The operations in both reactors revealed that nitrogen and phosphorus removal efficiencies increased with an increase in external carbon addition, reaching more than $90 \%$ at an external carbon addition of $45.0 \mathrm{mg}-\mathrm{C} / \mathrm{L}$. Moreover, the ratio of anoxic/oxic phosphate uptake rate (PUR), an index reflecting a fraction of denitrifying phosphate-accumulating organisms (DNPAOs) in total PAOs, indicates that nitrogen and phosphorus removal efficiencies were enhanced as the PUR ratio increased. Quantitative fluorescence in situ hybridization (FISH) revealed that external carbon addition facilitated the activity of DNPAOs as well as that of glycogen-accumulating organisms (GAOs). The degree of nitrogen removal by denitrifying GAOs (DNGAOs) seemed to increase with an increase in the dosage of external carbon added.
\end{abstract}

Keywords: anaerobic/oxic/anoxic (AOA) process, denitrifying phosphate-accumulating organisms (DNPAOs), enhanced biological phosphorus removal (EBPR), glycogen-accumulating organisms (GAOs), sequencing batch reactor (SBR)

\section{INTRODUCTION}

In enhanced biological phosphorus removal (EBPR) systems, denitrifying phosphate-accumulating organisms (DNPAOs), known for similar metabolic behaviors as phosphate-accumulating organisms (PAOs), have been identified (e.g., Kuba et al., 1997). These organisms take up external organic carbons and store them as polyhydroxyalkanoate (PHA) in their cells under anaerobic condition, subsequently consuming the PHA to take up phosphate with nitrite or nitrate instead of oxygen as an electron acceptor (Ahn et al., 2002a). This inherent property is of engineering benefit to allow the treatment of wastewaters with low $\mathrm{TOC} / \mathrm{N}$ (or $\mathrm{COD} / \mathrm{N}$ ) ratio, e.g. food processing wastewater (Zeng et al., 2003). To harness the property of DNPAOs for simultaneous nitrogen and phosphorus removals in a single reactor, an anaerobic/oxic/anoxic (AOA) process with a sequencing batch reactor (SBR) was proposed (Tsuneda et al., 2006). In this process, anoxic phosphate uptake and denitrification can be simultaneously achieved by DNPAOs under anoxic condition since nitrification during oxic condition generates nitrite and nitrate indispensable for anoxic phosphate uptake by DNPAOs. Moreover, the AOA process requires no

Address correspondence to Satoshi Tsuneda, Department of Life Science and Medical Bioscience, Waseda University, Email: stsuneda@waseda.jp

Received April 28, 2010, Accepted December 15, 2010. 
recirculation of activated sludge from oxic to anoxic tanks like a continuous EBPR process, allowing the simultaneous nitrogen and phosphorus removal in a single reactor vessel. One challenge of the AOA process is the adjustment of PAOs' activity, leaving sufficient phosphate for DNPAOs to make the AOA process work properly. The strategy is the addition of external organic carbon at the beginning of oxic phase to retard phosphate uptake by PAOs (Soejima et al., 2006). This is derived from the special property of DNPAOs that is, they release phosphate while synthesizing PHA even in the presence of both electron donor and acceptor (Ahn et al. 2002b). The addition of external carbon eventually creates the anoxic environment where DNPAOs can take up phosphate with nitrite or nitrate produced in the previous oxic phase. Although previous studies have indicated that the addition of external carbon at the beginning of oxic phase contributes to high nitrogen and phosphorus removal efficiencies in the AOA process, the effects of the amount of external carbon on nutrient removal performances and microbial community have not yet been investigated. The AOA process is required to enrich PAOs and DNPAOs over glycogen-accumulating organisms (GAOs), taking up organic carbons by glycolysis without phosphate release. Given these aspects, this study was undertaken to investigate the nitrogen and phosphorus removal efficiencies of the AOA process with different amounts of external carbon and the resultant PAOs/GAOs abundances in activated sludge.

\section{MATERIALS AND METHODS SBR operation}

Two AOA-regime SBRs with a working volume of $2 \mathrm{~L}$ were operated. One cycle was 8 $\mathrm{h}$, consisting of a 15-min filling phase, a 90-min anaerobic phase, a 90-min oxic phase, a 195-min anoxic phase, a 65-min settling phase and a 25 -min withdrawing phase. The amount of substrate filling and supernatant withdrawing was $1 \mathrm{~L}$, providing a hydraulic retention time of $16 \mathrm{~h}$. At the end of anoxic phase, $145 \mathrm{~mL}$ of excess sludge was withdrawn per day, thereby ensuring a solid retention time (SRT) of 14 days. This operation provided a mixed liquor suspended solid (MLSS) concentration of 3,500 $\mathrm{mg}-\mathrm{SS} / \mathrm{L}$. Water temperature was maintained at $23 \pm 2{ }^{\circ} \mathrm{C}$. The SBRs were initiated with inoculum from a continuous EBPR process basin at a municipal wastewater treatment plant, providing 2,700 $\mathrm{mg}-\mathrm{SS} / \mathrm{L}$ as an initial MLSS concentration.

\section{Synthetic feed}

Synthetic wastewater, with composition similar to that of food processing wastewater, was used as the feeding solution: $307.4 \mathrm{mg}$ of $\mathrm{CH}_{3} \mathrm{COONa}(90 \mathrm{mg} / \mathrm{L}$ as TOC basis, equivalent to $240 \mathrm{mg}-\mathrm{COD} / \mathrm{L}), 131.8 \mathrm{mg}$ of $\mathrm{KH}_{2} \mathrm{PO}_{4}\left(30 \mathrm{mg} / \mathrm{L}\right.$ as $\mathrm{PO}_{4}{ }^{3-}-\mathrm{P}$ basis$), 76.4$ and/or $152.8 \mathrm{mg} \mathrm{NH}{ }_{4} \mathrm{Cl}$ (20 and/or $40 \mathrm{mg} / \mathrm{L}$ as total nitrogen (T-N) basis), $14 \mathrm{mg}$ of $\mathrm{CaCl}_{2} \cdot 2 \mathrm{H}_{2} \mathrm{O}, 90 \mathrm{mg}$ of $\mathrm{MgSO}_{4} \cdot 7 \mathrm{H}_{2} \mathrm{O}$ and $0.3 \mathrm{~mL}$ of trace element solution per liter. The solution consisted of the following compounds per liter: $1.5 \mathrm{~g}$ of $\mathrm{FeCl}_{3} \cdot 6 \mathrm{H}_{2} \mathrm{O}, 0.15 \mathrm{~g}$ of $\mathrm{H}_{3} \mathrm{BO}_{3}, 0.03 \mathrm{~g}$ of $\mathrm{CuSO}_{4} \cdot 5 \mathrm{H}_{2} \mathrm{O}, 0.18 \mathrm{~g}$ of $\mathrm{KI}, 0.12 \mathrm{~g}$ of $\mathrm{MnCl}_{2} \cdot 4 \mathrm{H}_{2} \mathrm{O}, 0.06 \mathrm{~g}$ of $\mathrm{Na}_{2} \mathrm{MoO}_{4} \cdot 2 \mathrm{H}_{2} \mathrm{O}, 0.12 \mathrm{~g}$ of $\mathrm{ZnSO}_{4} \cdot 7 \mathrm{H}_{2} \mathrm{O}, 0.15 \mathrm{~g}$ of $\mathrm{CoCl}_{2} \cdot 6 \mathrm{H}_{2} \mathrm{O}$, and $10 \mathrm{~g}$ of EDTA (Smolders et al., 1994). No particulate organic carbon was contained in the wastewater. The $\mathrm{pH}$ of the synthetic wastewater was 7.2.

\section{Experimental conditions}

The two reactors were operated with the conditions as shown in Table 1 . Runs 1 and 2 
Table 1 - Operational conditions of the AOA processes

\begin{tabular}{cccc}
\hline \multirow{2}{*}{ Period } & \multirow{2}{*}{ Day } & \multicolumn{3}{c}{ Added TOC $[\mathrm{mg}-\mathrm{C} / \mathrm{L}]$} \\
& & Run 1 $(\mathrm{T}-\mathrm{N} 20 \mathrm{mg}-\mathrm{N} / \mathrm{L})$ & Run 2 \\
& $0-42$ & 0.0 & 0.0 \\
1 & $43-85$ & 11.0 & 11.0 \\
3 & $86-128$ & 22.5 & 22.5 \\
4 & $129-190$ & 45.0 & 45.0 \\
\hline
\end{tabular}

received different influent TOC/N ratios of 4.5 and 2.2, respectively. Sodium acetate as an external carbon was added at the beginning of the oxic phase in the reactors, where TOC concentrations were ensured to be $0,11.0,22.5$, and $45.0 \mathrm{mg} / \mathrm{L}$ for periods 1 to 4 , respectively, of both runs. Each period was set at more than three times longer than the SRT setting to stabilize the microbial community.

\section{Analytical methods}

Analyses of phosphate, MLSS and mixed liquor volatile suspended solid (MLVSS) were demonstrated according to AWWA Standard Methods (1992). Nitrite and nitrate concentrations were measured by a high-performance liquid chromatography with an anionic column (IC-Anion-PW, Tosoh, Japan) and an ultraviolet detector (UV-8011, Tosoh, Japan). Dissolved organic carbon (DOC) was measured by an automatic TOC analyzer (TOC-5000A, Shimadzu, Japan).

\section{Fluorescence in situ hybridization (FISH)}

Fluorescence in situ hybridization (FISH) was performed according to the standard hybridization protocol by Amann (1995). Sludge samples were taken from the reactors and were fixed immediately with freshly prepared $4 \%$ paraformaldehyde solution for 2 $\mathrm{h}$ at $4^{\circ} \mathrm{C}$. The $16 \mathrm{~S}$ rRNA gene targeting oligonucleotide probes and the formamide concentration used in this study were based on the study of Soejima et al. (2008). A confocal laser-scanning microscope (IX71, Olympus, Japan) equipped with an Ar ion laser $(488 \mathrm{~nm})$ and a HeNe laser $(543 \mathrm{~nm})$ was used to detect and record the ratio of probe-stained cells over total bacterial cells as a fraction of targeted bacteria.

\section{Evaluation of phosphate uptake rate}

A sludge sample $(150 \mathrm{~mL})$ taken at the end of anaerobic phase was transferred into two bottles. Each bottle was purged with nitrogen gas for $30 \mathrm{~min}$ to eliminate dissolved oxygen. One bottle received aeration and the other received $\mathrm{NaNO}_{3}$ of $20 \mathrm{mg}-\mathrm{N} / \mathrm{L}$ without aeration. Phosphate concentration was measured every $15 \mathrm{~min}$ for $90 \mathrm{~min}$ in each bottle. Oxic and anoxic phosphate uptake rates (PURs) per biomass weight (MLVSS) were determined by measuring a slope of a linear decrease in phosphate concentration. The ratio of anoxic PUR to oxic PUR (anoxic/oxic PUR ratio) was employed as a relative percentage of phosphate uptake by DNPAOs over total PAOs (Wachtmeister et al. 1997).

\section{RESULTS AND DISCUSSION}

\section{TOC, nitrogen and phosphorus removal efficiencies}

Influent and effluent concentrations of the AOA reactors are shown in Fig. 1. Overall, TOC removal efficiency was more than $95 \%$ in the two reactors. Effluent nitrogen and 
(A)

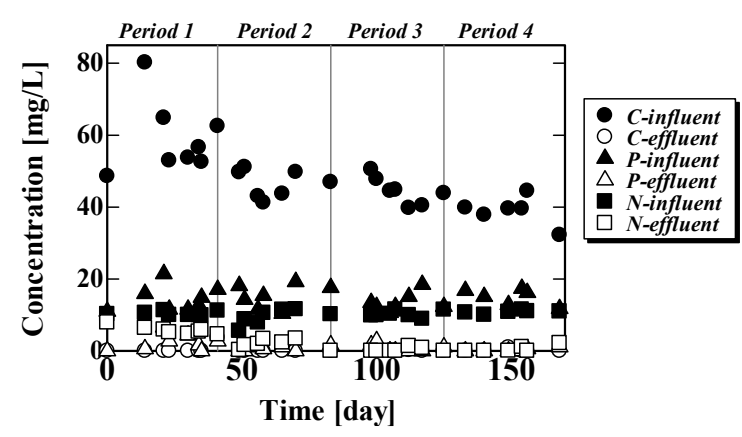

(B)

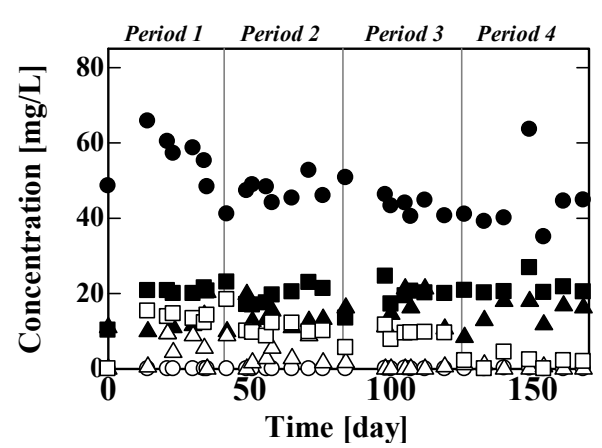

Fig. 1 - Time courses of organic carbon, nitrogen and phosphorus concentrations in the influent and effluent of (A) Run 1 and (B) Run 2

(A)

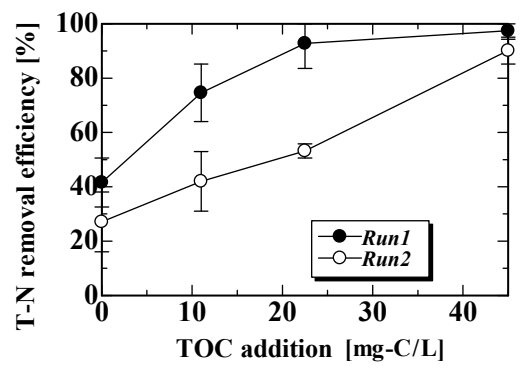

(B)

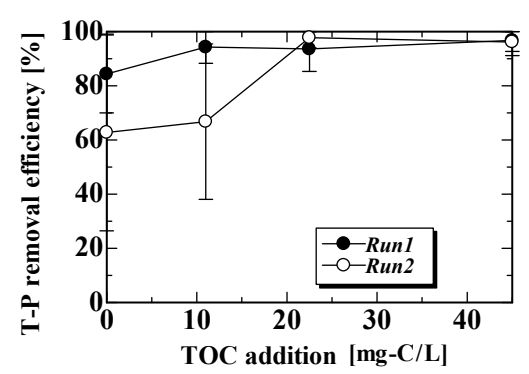

Fig. 2 -Nitrogen (A) and phosphorus (B) removal efficiencies of AOA processes at different dosages of external carbon $(n=7)$

phosphorus concentrations in both reactors decreased with an increase in the amount of external carbon addition, indicating the significance of external carbon addition to achieve high nitrogen and phosphorus removal efficiencies. The average removal efficiencies of nitrogen and phosphorus at the end of an SBR cycle are shown in Fig. 2. Higher nitrogen and phosphorus removal efficiencies were acquired with an increase in the amount of external carbon addition. Without external carbon addition (TOC addition: $0 \mathrm{mg}-\mathrm{C} / \mathrm{L}$ ), average nitrogen and phosphorus removal efficiencies were as low as $27.1-41.6 \%$ and $62.8-84.4 \%$, respectively. This indicates that high removal efficiencies, especially T-N, were contingent upon the addition of external carbon before oxic phase (F-test $\alpha=0.05$ ). At external carbon addition of $45.0 \mathrm{mg}-\mathrm{C} / \mathrm{L}$, both nitrogen and phosphorus removal efficiencies reached more than $90 \%$ in Runs 1 and 2 . The addition at the beginning of oxic phase has exhibited higher removal efficiencies than at the end of oxic phase mimicking anaerobic/oxic regime followed by heterotrophic denitrification by adding external carbon (Soejima et al., 2006). Hence, the receiving external carbon at the beginning of oxic phase allowed the efficient simultaneous removals of nitrogen and phosphorus which was probably due to the activation of DNPAOs. Moreover, the amount of external carbon required for sufficient removal efficiencies of nitrogen and phosphorus (e.g., > 90\%) was larger in Run 2 (T-N in influent: $40 \mathrm{mg} / \mathrm{L}$ ) than in Run 1 (T-N in influent: $20 \mathrm{mg} / \mathrm{L}$ ) (F-test $\alpha=0.05$ ). 


\section{One-cycle profile of the AOA process}

Fig. 3 shows the one-cycle profiles of carbon, nitrogen and phosphate with different TOC/N ratios in influent and added external carbon concentrations. Without the external carbon addition (Fig. 3(A)), the phosphate uptake was almost completed at the end of the oxic phase, and a phosphorus removal efficiency of $96.2 \%$ was attained. Denitrification was not observed at the anoxic phase due to phosphate depletion, leading to nitrate concentration as high as $5.8 \mathrm{mg} / \mathrm{L}$ at the end of one cycle. As a result, nitrogen removal efficiency was as low as 41.3\% (Fig. 3(A)). In contrast, Fig. 3(B) and 3(C) show one-cycle profiles on the addition of external carbon (TOC concentrations of 45.0 $\mathrm{mg} / \mathrm{L}$ ) at the beginning of oxic phase at influent T-N concentrations of 20 and $40 \mathrm{mg} / \mathrm{L}$. Phosphate concentrations were 5.6 and $14.6 \mathrm{mg} / \mathrm{L}$ for influent T-N concentrations of 20 and $40 \mathrm{mg} / \mathrm{L}$ at the end of the oxic phases, respectively. These results clearly indicate that the oxic phosphate uptake by PAOs was suppressed by the addition of external carbon, and consequently, phosphorus removal was not completed at the end of the oxic phase. This is probably because the addition of external carbon produces reduction equivalents through the TCA cycle in the presence of external carbon, leading to PHA production with phosphate uptake under oxic condition as previously reported (Ahn et al., 2002b).

\section{Phosphate uptake rates and microbial community composition}

The results of quantitative FISH are shown in Table 2. The application of the AOA operational regime successfully increased the fractions of PAOs and decreased the fractions of GAOs in both reactors (Period 1). The external carbon addition decreased the fractions of GAOs further (Period 2 in Runs 1 and 2) but gradually increased the fractions with an increase in external carbon addition (Periods 3 and 4). This indicates that the excess or shortage of external carbon determined the competition between PAOs and GAOs for organic carbon. Ammonia-oxidizing bacteria were enriched with the external carbon addition (from Period 1 to Period 2) while the fractions of nitrite-oxidizing bacteria were unchanged throughout the AOA operations.

Relative percentages of phosphate uptake by DNPAOs and PAOs/GAOs ratios as a function of external carbon addition are shown in Fig. 4. At an external carbon concentration of $11.0 \mathrm{mg}-\mathrm{C} / \mathrm{L}$, the relative abundance of PAOs/GAOs reached the maximum value of 11.8 and 8.8 in Runs 1 and 2, respectively, which were 7.3-fold and 5.5-fold higher than that in the inoculum. This suggests that the AOA process at an appropriate dosage of external carbon successfully enriched PAOs but not GAOs in

(A)

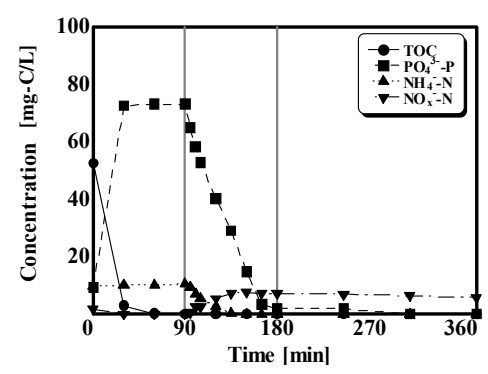

(B)

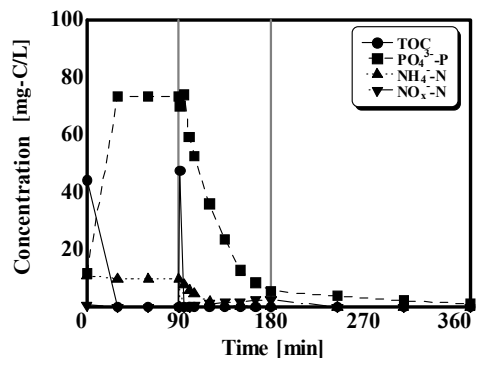

(C)

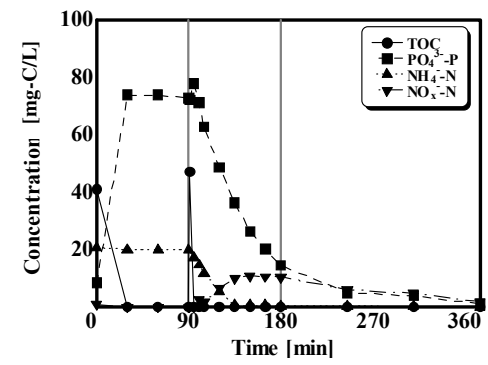

Fig. 3 - One-cycle profiles of carbon, nitrogen and phosphate at (A) Run 1-Period 1; (B) Run 1-Period 4; and (C) Run 2-Period 4 
Table 2 - Summary of microbial community composition in the inoculum and two AOAs by quantitative FISH in Runs 1 and $2(\mathrm{n}=10)$

(A) Run 1

\begin{tabular}{clccccc}
\hline \multirow{2}{*}{ Probe } & Target & Inoculum & Period 1 & Period 2 & Period 3 & Period 4 \\
\hline PAOmix & PAOs & $24.9 \pm 6.8$ & $33.6 \pm 9.1$ & $29.3 \pm 3.1$ & $31.2 \pm 3.4$ & $22.5 \pm 3.5$ \\
GAOmix & GAOs & $15.5 \pm 5.7$ & $6.1 \pm 2.8$ & $2.5 \pm 0.6$ & $5.5 \pm 1.4$ & $8.0 \pm 1.0$ \\
NSO190 & $\begin{array}{l}\beta \text {-Proteobacterial } \\
\text { ammonia-oxidizing bacteria }\end{array}$ & $3.2 \pm 2.5$ & $5.4 \pm 2.0$ & $11.9 \pm 2.6$ & $9.6 \pm 3.7$ & $6.8 \pm 2.5$ \\
Ntspa662 & $\begin{array}{l}\text { Nitrospira-like } \\
\text { nitrite-oxidizing bacteria }\end{array}$ & $1.0 \pm 0.4$ & $0.9 \pm 0.6$ & $0.4 \pm 0.3$ & $0.6 \pm 0.3$ & $1.0 \pm 0.5$ \\
\hline
\end{tabular}

(B) Run 2

\begin{tabular}{clccccc}
\hline \multirow{2}{*}{ Probe } & Target & Inoculum & Period 1 & Period 2 & Period 3 & Period 4 \\
\hline PAOmix & PAOs & $24.9 \pm 6.8$ & $33.5 \pm 9.0$ & $27.8 \pm 5.0$ & $38.8 \pm 6.6$ & $32.3 \pm 5.9$ \\
GAOmix & GAOs & $15.5 \pm 5.7$ & $6.1 \pm 2.7$ & $3.2 \pm 0.4$ & $6.2 \pm 2.9$ & $8.3 \pm 1.7$ \\
\multirow{2}{*}{ NSO190 } & $\begin{array}{l}\beta \text {-Proteobacterial } \\
\text { ammonia-oxidizing bacteria }\end{array}$ & $3.2 \pm 2.5$ & $5.3 \pm 1.9$ & $8.5 \pm 4.2$ & $12.0 \pm 3.6$ & $8.4 \pm 1.3$ \\
Ntspa662 & $\begin{array}{l}\text { Nitrospira-like } \\
\text { nitrite-oxidizing bacteria }\end{array}$ & $1.0 \pm 0.4$ & $0.9 \pm 0.6$ & $0.9 \pm 0.6$ & $0.8 \pm 0.7$ & $0.6 \pm 0.3$ \\
\hline
\end{tabular}

(A)

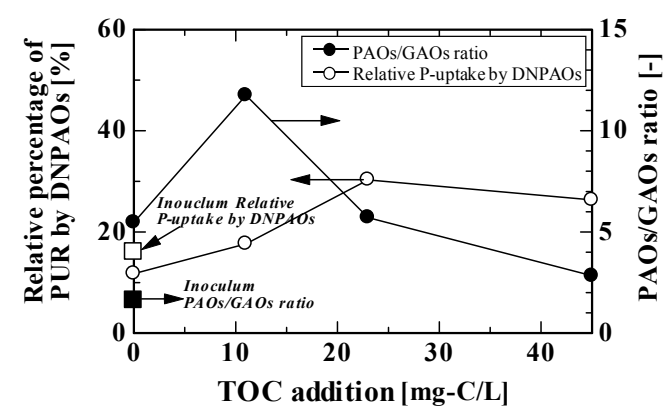

(B)

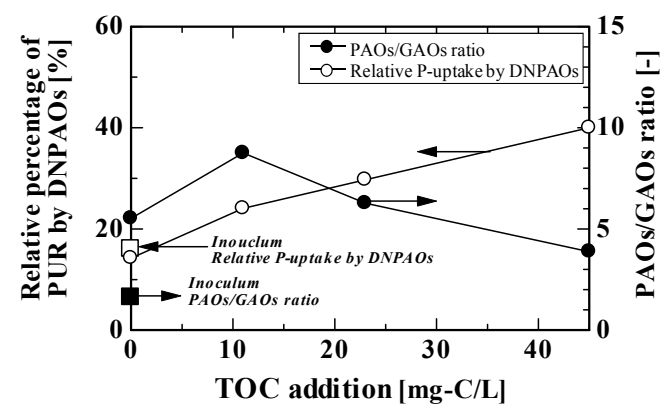

Fig. 4 - Relative percentage of PUR by DNPAOs and PAOs/GAOs ratio as a function of the amount of external carbon addition in Run 1 (T-N $20 \mathrm{mg} / \mathrm{L} ;(\mathrm{A})$ ) and Run 2 (T-N $40 \mathrm{mg} / \mathrm{L} ;(\mathrm{B})$ )

activated sludge. Incorporating the trends in Fig. 2, nitrogen and phosphorus removal efficiencies probably increased due to an increase in the relative percentage of PUR by DNPAOs, supporting the significance of DNPAOs in the AOA process.

An increase in the external carbon addition led to an increase in the relative percentage of phosphate uptake by DNPAOs but a decrease in the PAOs/GAOs ratio was obtained at the external carbon addition of more than $22.0 \mathrm{mg}-\mathrm{C} / \mathrm{L}$. Especially in Run 2, an increase in the relative phosphate uptake by DNPAOs negatively correlated with PAOs/GAOs ratio, suggesting that not only DNPAOs but also DNGAOs were responsible for denitrification. This result is congruent with the previous study showing that GAOs are denitrifying (e.g. Zeng et al., 2003). Putatively, the excessive external carbon addition provided a chance for GAOs to take up carbon, potentially leading to a 
decrease in PURs. On the contrary, some GAOs could be denitrifying, which plausibly boosts denitrification potential in the AOA process. The detailed contribution of DNPAOs and DNGAOs warrants future study. The optimization of the amount of external carbon according to the incoming wastewater composition, i.e. TOC/ $\mathrm{N}$ ratio, should also be conducted.

\section{Conclusion}

Two AOA-regime SBRs were operated to investigate the effect of external carbon addition for nitrogen and phosphorus removal. Bacterial population in the SBRs with different T-N concentrations was analyzed to elucidate the relationship between nutrient removal efficiencies and PAOs/GAOs ratios. The main conclusions are as follows:

(1) External organic carbon addition of $45.0 \mathrm{mg}-\mathrm{C} / \mathrm{L}$ for $\mathrm{T}-\mathrm{N}$ of 20 and $40 \mathrm{mg}-\mathrm{N} / \mathrm{L}$ permitted high nitrogen and phosphorus removal efficiencies of more than $90 \%$, probably due to the enrichment of DNPAOs and DNGAOs in the AOA process.

(2) The activity of DNPAOs correlated with nitrogen and phosphorus removal efficiencies, suggesting that they should be a key player to achieve high nutrient removal in the AOA process especially at external carbon addition of $11.0 \mathrm{mg}-\mathrm{C} / \mathrm{L}$ irrespective of the applied T-N concentrations.

(3) An external carbon addition of more than $22.5 \mathrm{mg}-\mathrm{C} / \mathrm{L}$ potentially enriched DNGAOs, which contributes to denitrification but not for phosphate uptake.

Therefore, careful operation regarding external carbon addition at the beginning of oxic phase is essential to achieve stable nitrogen and phosphate removal in the AOA process.

\section{REFERENCES}

Ahn J., Daidou T., Tsuneda S. and Hirata A. (2002a). Characterization of denitrifying phosphate-accumulating organisms cultivated under different electron acceptor conditions using polymerase chain reaction-denaturing gradient gel electrophoresis assay, Water Res., 36(2), 403-412.

Ahn J., Daidou T., Tsuneda S. and Hirata A. (2002b). Transformation of phosphorus and relevant intracellular compounds by a phosphorus-accumulating enrichment culture in the presence of both the electron acceptor and electron donor, Biotechnol. Bioeng., 79(1), 83-93.

Amann R. (1995). In situ identification of microorganisms by whole cell hybridization with rRNA-targeted nucleic acid probes, In: A. D. C Akkermans, J. D. van Elsas, F. J. de Brujin, editors. Molecular Microbial Ecology Manual, Kluwer Academic Publisher, Dordrecht, The Netherlands, pp.1-15.

Kuba T., van Loosdrecht M. C. M., Brandse F. A. and Heijnen J. J. (1997). Occurrence of denitrifying phosphorus removing bacteria in modified UCT-type wastewater treatment plants, Water Res., 31(4) 777-786.

Smolders G. J. F., van der Meij J., van Loosdrecht M. C. M. and Heijnen J. J. (1994). Stoichiometric model of the aerobic metabolism of the biological phosphorus removal process, Biotechnol. Bioeng., 44(7), 837-848.

Soejima K., Oki K., Terada A., Tsuneda S. and Hirata A. (2006). Effects of acetate and nitrite addition on fraction of denitrifying phosphate-accumulating organisms and nutrient removal efficiency in anaerobic/aerobic/anoxic process, Bioprocess Biosyst. Eng., 29(5-6), 305-313.

Soejima K., Matsumoto S., Ohgushi S., Naraki K., Terada A., Tsuneda S. and Hirata A. (2008). Modeling and experimental study on the anaerobic/aerobic/anoxic process for 
nitrogen and phosphorus removal: The effect of acetate addition, Process Biochem., 43(6) 605-614.

Standard methods for the examination of water and wastewater (1992). 18th edn., American Public Health Association/American Water Works Association/American Environment Federation, Washington DC, USA.

Tsuneda S., Ohno T., Soejima K. and Hirata A. (2006). Simultaneous nitrogen and phosphorus removal using denitrifying phosphate-accumulating organisms in a sequencing batch reactor, Biochem. Eng. J., 27(3) 191-196.

Wachtmeister A., Kuba T., van Loosdrecht M. C. M., Heijnen J. J. (1997). A sludge characterization assay for aerobic and denitrifying phosphorus removing sludge, Water Res., 31(3), 471-478.

Zeng R. J., Lemaire R., Yuan Z. and Keller J. (2003). Simultaneous nitrification, denitrification, and phosphorus removal in a lab-scale sequencing batch reactor, Biotechnol. Bioeng., 84(2), 170-178. 